\title{
REFLEXÕES ACERCA DA ABORDAGEM SOCIOLÓGICA DO CRESCIMENTO E DO DESENVOLVIMENTO DA CRIANÇA NO CAMPO DA SAUDE PUBLICA: - ASPECTOS TEÓRICO-METODOLÓGICOS*
}

\author{
Augusta Thereza de Alvarenga ${ }^{1}$
}

\begin{abstract}
ALVARENGA, A. T. Reflexões acerca da Abordagem Sociológica do Crescimento e do Desenvolvimento da Criança no Campo da Saúde Pública Aspectos Teórico-Metodológicos. Rev. Bras. Cresc. Des. Hum. 1(2): 1991.

RESUMO

No presente trabalho procuramos refletir sobre a importância do estudo interdisciplinar sobre o crescimento e o desenvolvimento da criança no campo da Saúde Pública, quer sob a ática do avanço do conhecimento científico, quer da prática de intervenção. A partir de abordagem sociológica capaz de problematizar pontos controversos e desafiadores para os dois níveis de atuação, destacamos, por um lado, 0 falo de 0 crescimento e de 0 desenvolvimento serem tratados de forma dissociada por diferentes áreas de conhecimento e de prática, tais como a saúde, a psicologia e a educação. Por outro lado, destacamos a tendência ao emprego recorrente de esquemas teórico-metodológicos de investigação que operam, no campo da saúde, uma redução do fenómeno crescimento e desenvolvimento a paradigmas dos campos da biologia ou das ciência naturais e, nos campos da psicologia e educação, a redução do desenvolvimento aos da psicologia. Tendo em vista relevantes questões sociológicos perpassarem os diferentes níveis de tratamento da questão, buscamos abordá-las a partir de
\end{abstract}

um quadro de referência teórico-metodológico no qual o processo de reprodução social pudesse ser identificado como instrumental capaz de resgatar espaços sociais de classe onde a criança cresce e se desenvolve de forma diferencial e típica

Abordar o crescimento e o desenvolvimento da criança como problema de natureza social é tarefa altamente frutífera, mas sobretudo desafiante, tendo em vista os vários aspectos envolvidos numa reflexão aprofundada sobre o assunto.

No entanto, nosso propósito no momento não é o de realizar grandes incursões no interior da sociologia, mas tão-somente recuperar alguns dos aspectos teórico-metodológicos que consideramos relevantes para a análise do problema, conforme temse apresentado em nível da nossa prática profissional, a Saúde Pública, constituindo-se em desafio nos estudos multidisciplinares empreendidos.

Neste particular, o pressuposto básico de que partimos é o de que o crescimento e o desenvolvimento são os melhores indicadores para caracterizar o nível de saúde da população infantil. Isto porque, ao usá-los, estamos empregando o que se conhece, na área, como indicadores “positivos” das condições de saúde e não indicadores "negativos", a exemplo do que fazemos quando medimos o nível de saúde por meio do dano maior, a morte, esse definido pelas taxas de mortalidade. ${ }^{2}$

\section{CARACTERIZANDO O PROBLEMA}

O que queremos de início relevar é o fala de que, se pudermos conhecer e trabalhar com a

\footnotetext{
* Versão de palestra preferida em mesa-redonda sobre “Crescimento e Desenvolvimento”, no Seminário “Encontro sobre Creches”, promovido pelo CDH e pela Faculdade de Saúde Pública/USP, em São Paulo, em outubro/86.

1 Professora-doutora do Departamento de Saúde Materno-lnfantil da Faculdade de Saúde Pública/USP - Av. Dr. Arnaldo, 715 - CEP 01255 - São Paulo - SP.

2 Ver a esse propósito trabalho de CLAUDET, P. T. et alii (1977).
} 
essencialidade do processo de crescimento e de desenvolvimento da criança, recuperamos, em nível da análise, e aluamos, em nível da prática, sobre a manifestacão viva das forças sociais que são objetivadas, ou seja, concretizadas, quer no ato de a criança nascer, quer no de ela poder crescer e desenvolver-se segundo as potencialidades - por que não dizer? - da própria espécie humana (já reveladas ao que parece, pelas elevadas condições de vida de determinadas "sociedades avançadas”). Da mesma maneira, essa manifestação viva das forças sociais se concretiza e, portanto, se Totaliza quando esses processos - de nascer, crescer e desenvolver - são interrompidos pela morte prematura, ou dificultados, quer por morbidades especificas e típicas de determinadas condições de vida, quer, sobretudo, por ações inadequadas das várias práticas sociais institucionalizadas que tomam, para si, a responsabilidade do cuidado da criança, como a Saúde e a Educação. Em outras palavras, a idéia básica que passamos a defender é a de que tanto o crescimento físico quanto o desenvolvimento somático (vistos como objeto de estudo da área da Saúde) e, também, os desenvolvimentos cognitivo, afetivo e social (tomados como questões especificas das áreas da psicologia e da educação), são “fenómenos" socialmente determinados através de formas típicas de reprodução social, presentes no interior da sociedade.

Julgamos ser essa questão fundamental visto que, no seu processo de crescimento e de desenvolvimento, em função de suas características de "ser imatura" e dependente, a criança é submetida a relações sociais definidas, que passam a expressar a forma pela qual a sociedade "cuida" dos corpos, das mentes e das consciências. Revelam, em suma, a forma pela qual relações sociais definem processos típicos de crescimento e de desenvolvimento da criança, no interior da mesma sociedade, de acordo com a sua inscrição em classes sociais determinadas.

Posto serem o crescimento e o desenvolvimento considerados, tanto na saúde quanto na educação, um processo organizado, contínuo, regular, sincrônico e mesmo com uma sequência fixa de estádios, a questão que se coloca para a análise é a de corno entendemos e trabalhamos com as especificidades de cada um desses processos, em termos de sua natureza e das relações que ambos mantêm entre si.

Esta questão é relevante tendo em vista que o interesse cada vez maior na criança, e particularmente no seu bem-estar, tem a ver com a forma pela qual ela nasce, cresce e se desenvolve, não somente em função das condições familiares a que é submetida, por pertencer a determinada classe social, mas também em função de como ela vem sendo entendida e tratada, notadamente no nível daquelas práticas institucionais, onde as questões do crescimento e do desenvolvimento se colocam, de maneira mais explícita, como objeto do trabalho de especialistas.

Procurando reter mais particularmente a segunda parte dessa questão, o primeiro aspecto a considerar é o de como a área de Saúde vem tratando a questão do crescimento e do desenvolvimento da criança, do ponto de vista do conhecimento científico e da prática de intervenção.

\section{CONCEPCÕES PRESENTES NA SAÚDE, EDUCAÇÃO E PSICOLOGIA}

Embora vários aspectos estejam em jogo na análise do próblema, o que pretendemos destacar, do ponto de vista do conhecimento, é que os estudos da área da Saúde sobre crescimento e desenvolvimento, tomados como fenômenos diferenciados em sua natureza, são, na realidade, muitas vezes confundidos e normalmente reduzidos a parâmetros genéticos e organicos, em termos da sua expressão final. Ou seja, por um lado, o crescimento é concebido como o aumento das dimensões somáticas (peso, altura, volume) e, por outro, o desenvolvimento é considerado - via fenômenos de maturação, diferenciação anatômica, histológica e bioquímica - em fenômeno de aperfeiçoamento e aqutsição funcionais.

Embora estudos da área revelem a diferenciação entre esses dois processos e considerem que não há nenhum período da vida em que haja crescimento sem maturação, isto é, crescimento sem alterações na composição ou funções (do organismo humano), o falo a destacar é o de que o crescimento e o desenvolvimento passam a ser considerados, para a maioria dos investigadores procedentes das ares das ciências biológicas, como etapas de um mesmo processo que se traduz - de maneira indiferenciada - na maturação do organismo. Daí podermos observar que, por um lado, clássicos autores dessa área, como, por exemplo, Gruenwald (1966), tomam os dois termos como sinônimos, como expressão de um mesmo processo biológico, entendido como o crescimento e o desenvolvimento somático; e que, por outro lado, a literatura especializada apresenta estudos onde crescimento 6 tomado como expressão de ambos os processos (Patri e cols. (1979); Rode \& Shephard (1984); Mardones-Restat \& Jones (1987); Rallison (1987); Kitchen e cols. (1989)).

Tal ocorrência gera implicações para o processo de conhecimento por representar uma forma de redução teórico-metodológica 
descaracterizadora da natureza do objeto. Por um lado, limita a explicação sobre as condições de saúde da criança e, por outro lado, a inscreve em modelos ideais, notadamente de crescimento, como explicativos de suas condições de saúde e de doença

Desse modo, a despeito da relevancia de se considerar os processos de crescimento e de desenvolvimento como os melhores indicadores para caracterizar o nível de saúde da população, o que constatamos são as dificuldades de se conhecerem as reais condições de saúde da população infantil com base unicamente na tradição de pesquisa existente no campo. Pelo "paradigma"3 de investigação vigente, fundado basicamente em termos biológicos, a relação do crescimento com os processos de desenvolvimento, que simultaneamente ocorrem com a criança, se perde. Considerando que a articulação dos mesmos, ao lado das condições sociais de classe, determina as suas condições de saúde, podemos observar os limites e as implicações decorrentes dessa forma de redução.

Se, para os investigadores da área biológica - predominantes no campo da Saúde -, a questão do desenvolvimento reduz-se a esta dimensão somática, traduzida num processo que abarca tanto a quantidade como a qualidade das mudanças de maturação de maneira indifereciada, no caso de investigadores das áreas da Educação e da Psicologia, o tratamento do problema difere.

Para estas áreas, o que se verifica é que, em função de seus objetivos, a questão do crescimento não se coloca enquanto tal e a do desenvolvimento assume características diversas; ou seja, qualifica-se como outro tipo de problema, pois passa a ser definido e tratado nas suas dimensões cognitiva, afetiva e social.

Malgrado o nível de avanço teórico nesses campos, o falo a Considerar é o de que o conhecimento científico compartimentado - em nível das áreas que trabalham com a questão - promove, no estudo da criança, uma fragmentação direcionada a um ou mais aspectos dos processos de crescimento e, mais especificamente, do desenvolvimento infantil, levando, com isso, a abordagens parcializadas do problema.

Assim, para as áreas da Psicologia e da Educação, as relações existentes entre os processos de crescimento-desenvolvimento somático e de desenvolvimento (cognitivo, afetivo e social) não se constituem em objeto de preocupação, da mesma maneira que para a área da Saúde.

Para a maioria desses investigadores o marco biológico tem constituído interesse somente na medida em que os falares genéticos e fisiológicos incidem negativamente sobre o processo, limitando ou bloqueando, principalmente, o que consideram ser o adequado desenvolvimento intelectual da criança.

Com essa visão, e de acordo com o seu objeto de interesse, educadores e psicólogos têm centrado seus estudos no papel dos fatoies de aprendizagem cognitivo e social, assim como nos aspectos da vida emocional e motivacional da criança, embora nem sempre sejam tratados, entre si, de maneira articulada.

Diante disso, o que pretendemos ressaltar é que esse processo de atomização, que se dá em nível do conhecimento, tem implicações tanto para a prática da saúde quanto da educação, uma vez que se observa que as propostas institucionais de trabalho dessas duas áreas, que se ocupam da criança nessa fase de sua vida, reproduzem, de maneira característica, essa visão fragmentada, em diferentes níveis.

Nesse particular, ganha expressão a observação de Kuhn (1975) quando se refere ao falo de que a presença de dada tradição da prática científica, constitutiva do que nomeia como "ciência normal” — paradigmal —, acaba, implicitamente, por definir, de um lado, problemas e métodos "legítimos" de dado campo de pesquisa para gerações de investigadores, e de outro, formas típicas de solução desses problemas.

\section{SOBRE A NATUREZA SOCIAL DO CRESCIMENTO E DO DESENVOLVIMENTO DA CRANÇA}

Os falos anteriormente expostos, que, em síntese, revelam a própria concepção que a sociedade tem da criança, também expressam, conforme já mencionamos, a forma típica pela qual a mesma, em função de relações sociais definidas, passa a "cuidar" dos corpos, das mentes e das consciências. Essa concepção adquire relevância sociológica para a análise da questão do crescimento e do desenvolvimento da criança uma vez que é a partir de tais relações que esses fenómenos se concretizam e se apresentam de forma objetivada no interior da sociedade.

3 Entendemos o conceito de paradigma, a partir de Kubn (1975), como dada prática científica no campo da saúde, estruturada com baae numa tradição de pesquisa calcada em regras e padrões de natureza teórico-metodológica compartilhados pela naioria dos investigadores da área. 
O que pretendemos salientar com isso é que dentro de determinada postura sociológica é possível reter - identificar e explicar - os diferentes significados atribuidos aos termos crescimento e desenvolvimento da criança, tanto em nível de seu emprego no processo de conhecimento quanto de sua aplicação nas diferentes práticas sociais.

Isso é possível quando se toma, como referencial teórico para a análise da questão, a forma pela qual a sociedade se organiza, ou seja, se estrutura —no nosso caso de sociedade capitalista, em classes. Isto porque é característico das sociedades divididas em classes buscarem reproduzir condições tais que assegurem a consecução ou manutenção de determinados tipos de interesses - das classes dominantes-, quer sejam esses de natureza económica, política ou social, este último entendido, no sentido estrito do termo, como interesse ideológico. 0 que vale destacar é que valores socialmente determinados passam a ser reproduzidos através de mecanismos próprios, tradicionalmente denominados de "instituições sociais”, ou ainda, numa linguagem sociológica mais específica, de "Aparelhos Ideológicos de Estado". ${ }^{4}$ A consideração destes é fundamental nesse tipo de análise do crescimento e do desenvolvimento, uma vez que tanto a Saúde quanto a Educação passam a ser categorizados como Aparelhos de Estado, que apresentam formas diferenciais e típicas de atendimento à população infantil, de acordo com a realidade social na qual essa se inscreve.

Exemplo típico dessa reprodução de interesses pode ser observada quando buscamos aprofundar a análise do significado da adoção (consciente ou inconsciente) — em nfvel das práticas de educação e de saúde-de determinadas posturas teórico-metodológicas que visam a atingir as classes populares de maneira particular, tendo em vista objetivos definidos. Nesse sentido, representam faces de uma mesma estratégia, a da objetivação dos interesses de classe.

CRIANÇA - ESCOLA E SAÚDE: do abstrato padrão médio de crescimento e desenvolvimento infantil à descaracterização da realidade social da criança

O papel social atribuído à Escola no interior de diferentes sociedades, e em particular no Brasil, é esclarecedor desse processo e pode ser recuperado, em termos essenciais, através de algumas das considerações históricas realizadas por Sônia Kramer (1982a) quando de sua análise sobre a "Polftica do Pré-Escolar no Brasil", tema esse trabalhado como "A Arte do Disfarce". Essas considerações têm relevância na medida em que permitem indicar a forma típica pela qual a questão do desenvolvimento da criança de quatro a seis anos passou a ser encarada, enquanto proposta social a ser veiculada em diferentes contextos históricos, pelo trabalho pedagógico da PréEscola.

Segundo a autora, essa forma de atendimento à criança, que emerge na sociedade americana notadamente na década de 60 , caracterizase como uma proposta pedagógica, política e ideologicamente definida, ao apresentar-se como medida preventiva ao fracasso escolar de crianças pobres, consideradas, por definição, privadas culturalmente.

Essa forma de atendimento, que chegou a se constituir em 1965 em um projeto de assistência médica, dentária e de serviç̧os educacionais (Projeto Head Start), integrou, juntamente com outros projetos, um programa caracterizado como de natureza compensatória ${ }^{5}$ como parte da chamada "Guerra Contra a Pobreza", decretada pela administração Johnson.

Analisando essa proposta de reforma pedagógica nos Estados Unidos, Sônia Kramer (1982a) salienta, e critica, que a mesma é confundida com mudança social e, nela, a Pré Escola é divulgada como solução para problemas de diferentes ordens, notadamente os de natureza económica ou social. A noção básica impressa nesses programas compensatórios é a de que os pais não conseguem dar para os filhos_-privados culturalmente- a base para o "sucesso" na sociedade. Nesta estratégia, a Pré-Escola significaria uma ponte para a criança de hoje, e cidadão de amanhã, ultrapassar as barreiras existentes entre as classes sociais. ${ }^{6}$

Subjacente a essa noção, encontra-se outra que sustenta que as crianças, provenientes das classes populares, sofrem grandes desvantagens em termos da falta de estimulação no seu ambiente familiar, assim como da pobreza de linguagem de seus pais; principalmente de sua mãe. Com base nessa noção, esse argumento passa a ser reforçado pela idéia de que, ao chegarem à Escola Elementar, essas crianças fracassariam por não

4 Sobre o assunto ver, por exemplo, obra de ALTHUSSER, L. (Pág. 74).

5 Para uma interessante abordagem das estreitas relações existentes entre privação cultural e educação compensatória no interior dessa proposta, consultar Kramer, S. (1982b).

6 Para uma análise específica do papel social da Pré-Escola, ver igualmente Kramer, S. (1985). 
terem vivido diversas experiências, anteriores à escolarização, consideradas fundamentais para o êxito no desempenho escolar; desempenho esse medido a partir das características próprias que definem as crianças das classes sociais elevadas, no caso americano.

Em termos nacionais, o que nos interessa ressaltar é a constatação da autora de que essa proposta pedagógica emerge no Brasil na década de 70, trazendo, em seu bojo, esses mesmos preceitos e concebendo todas as crianças brasileiras a partir de uma suposta criança de classe média.

Tal concepção de trabalho pedagógico na Pré-Escola - que passa a considerar a criança a partir de um padrão médio, socialmente estabelecido, e o transforma num modelo ideal de comportamento e desempenho infantil - tem sérias implicações sociológicas quando se considera a questão do desenvolvimento da criança, quer no campo da Educação, quer no campo da Saúde.

Isto porque, ao representar um conceito abstraio de infancia, tal enfoque passa a escamotear e a falsear a criança enquanto ser” social, portanto, enquanto "ser" concreto, real, além de “ser” psicológico, individualizado e único. Não apreende, por suas características, a criança como ela realmente é, mas sim, como ela deveria ser à feição, portanto, "de dado modelo ideal. Nessa abstração, o desenvolvimento da criança passa a ser considerado co» independente das condições de vida; condições essas determinadas pela classe social a que pertence e em função da qual a criança partilha, com sua família, de um meio cultural típico, socialmente reproduzido para ela. Em outros termos, descaracteriza-se o falo de que ao participar de determinada situação a criança partilha de uma cultura típica, de classe, que é determinada pelas condições objetivas de existência, próprias de sua classe social.?

Como decorrência, destaca-se o falo de as crianças pertencentes às classes populares passarem a ser consideradas, a partir desse modelo, como carentes, deficientes e inferiores, na medida em que não correspondem ao padrão médio ideal de desempenho estabelecido. ${ }^{8}$
O problema ideológico que identificamos, com base nessa teoria que sustenta tal prática pedagógica, é o da concepção de que as dificuldades dessas crianças em responderem ao desempenho escolar exigido pelo modelo adorado passam, por um lado, a significar que as mesmas foram privadas apenas culturalmente, faltandolhes assim, tão simplesmente, determinados atributos ou conteúdos que nelas deveriam ser incutidos em nível da Pré-Escola. Além disso, em função de suas características, essa proposta passa a apresentar amplas possibilidades de justificar e, socialmente, legitimar a emergência, em nosso meio, de uma política educacional de natureza compensatória para responder às necessidades concretas das crianças pertencentes às classes populares.

Neste particular, uma questão sociológico relevante para a análise do desenvolvimento da criança centra-se, sobretudo, nas dificuldades decorrentes das barreiras ideológicas presentes, seja em nível das teorias, seja em nível das práticas institucionais que as sustentam, de se resgatar a natureza do desenvolvimento infiel til em sua expressão concreta.

Isto porque, na medida em que se "legitimam” somente tão rias de cunho idealista, abstratas e a-históricas para nortear a prática, a questão da caracterização da criança brasileira concreta, real, assim como a identificação de suas necessidades, perde-se em tipos e modelos ideais que s6 se "justificam” por responder a interesses específicos no interior do sistema.

Por isso, embora a idéia de privação cultural se manifesto, de maneira mais explícita, na educação, o falo é que, na realidade, ela permeia todas as áreas do conhecimento e das práticas que têm a criança como objeto de trabalho. É a reprodução da ideologia dominante que, assegurada pelas instituições sociais - melhor dizendo, pelos Aparatos de Estado_-veicula, de maneira típica, suas idéias e valores sobre a criança, em particular sobre a criança pobre, tendo em vista a manutenção de determinada ordem de interesses, de classe. Nesse sentido, o importante a observar é

7 Para um tratamento aprofundado desse tipo de análise, ver, por exemplo, trabalhos de Bourdieu, P. (1974), Bourdieu, P. \& Passeron, J. C. ( 1975).

8 Bastante sugestiva é uma das formas de como esse tipo de concepção encontra-se presente nas práticas de saúde. Em trabalho clássico sobre a Puericultura, Boltanski (1969) demonstra, por exemplo, como a ideologia da personalizarão opera na relação médico e paciente das classes populares. Resultado de uma percepção seletiva baseada em pacientes pertencestes às classes altas, as primeiras passam a ser consideradas incapazes de incorporar o saber médico, reservando, esse profissional, longas explicações somente àqueles - das classes elevadas - que julga suficientemente evoluídos para entenderem as explicações. Como desdobramento da questão, observa o autor que a verbalização do médico se reduz - no caso das classes baixasàs perguntas e ordens e, quando aparecem os conselhos, estes são frequentemente acompanhados de sanções, assimiladas às regras morais. 
que esses interesses são transmitidos através de Aparelhos de Estado e passados como interesses universais, sob a ilusão, portanto, de atenderem às necessidades de todas as classes sociais.

Assim, a exemplo da Escola, o mesmo tipo de prática pode ser observada no setor Saúde, na área da chamada Puericultura. Nesta, o que constatamos é que a questão do crescimento e do desenvolvimento passa a ser reduzida a uma padronização, seg^lindo parâmetros, como peso e estatura, em função de modelos de crescimento ideal, usualmente tomados de padrões internacionais, de países “desenvolvidos”.

Se até agora procuramos demonstrar o nosso tipo de preocupação com relação à questão das teorias de cunho idealista - que frequentemente norteiam os estudos de desenvolvimento e são prioritariamente incorporadas à prática institucional da escola -, queremos ressaltar, ao mesmo tempo, igual nível de preocupação com relação à postura positivista que tradicionalmente norteia o campo do conhecimento e das práticas institucionais na área da Saúde Pública ou Coletiva.

Como questão básica, destacamos o processo de redução que sofrem tanto o sociológico quanto o psicológico - quando da analise quer do crescimento, quer do desenvolvimento nesse campo - pela adoção quase exclusiva de uma forma de explicação biológica desses fenómenos, onde essas dimensões são pressupostamente contempladas. ${ }^{9}$ Especificando melhor, o que observamos é a desvinculação do "social” (e também do "psicológico”) de seus contextos teóricos de origem, por serem somente referidos, nomeados e tomados na condição de variaveis inscritas no interior de dado modelo teórico-metodológico, característico de uma tradição de pesquisa na área, cuja lógica interna se estrutura com base em fundamentos ontológicos e epistemológicos próprios do campo das ciências naturais (conforme exemplificam trabalhos como os de Apolloni \& Cooke (1975); Siegel (1982); Rappaport e cols. (1983); Bornschein (1985); Rona \& Chinn (1986); Schraeder (1986); Casey e cols. (1986); Mardones-Restat \& Jones (1987); Posada \& Esquivei (1987), dentre outros). Esse procedimento, se por um lado descaracteriza essas dimensões - igualmente definidoras da natureza dos fenómenos -, por outro lado, fragmenta a análise do processo que os identificaria ou os articularia em termos de sua expressão global. Além disso, é sobretudo na identificação de modelos ideais centrados em estudos de crescimento - moldados a partir de padrões encontrados para os pa ses avançados - que tanto o conhecimento quanto a prática no campo da saúde prioritariamente se estruturam.

\section{RESGATANDO A NATUREZA DO SOCIAL}

Diante dessa ordem de problemas, a idéia básica, a ser retida no tratamento da questão, é a de que o "social” presente na vida da criança não é um simples pano de fundo, como pretendem colocar aquelas teorias que o transforma em "tipo ideal” ou o fragmenta em múltiplas e infinitas variaveis como parte de esquemas sedutores. Trata-se, ao contrário, de um "social” determinante do espaço de vida, onde a criança, adscrita a uma dada condição de classe, se movimenta nos diferentes espaços institucionais a ela reservados, caracterizados, por exemplo, por diferentes modalidades de Pré-Escola. Nesse contexto, é necessário reter que a família não se constitui somente numa instituição ou num Aparelho de Estado, reconhecidamente importante para os cuidados relativos à assistência da criança, em seu processo de crescimento e desenvolvimento e, sobretudo, de socialização. Representa, essencialmente, as condições objetivas de existência, a partir das quais possibilidades concretas de crescimento e de desenvolvimento se definirão, tendo em vista sua inscrição em diferentes práticas sociais. Assim é que a opção pela préescola, do mesmo modo que por serviços de saúde_-públicos ou privados-, não é resultado de um simples desejo pessoal ou voluntário, mas sim de possibilidades objetivas de existência determinadas por cada classe social. É neste sentido que, desta perspectiva teóricometodológica, passamos a considerar os processos de crescimetno e de desenvolvimento da criança como a mais viva representação da reprodução das condições de classe às quais a criança se encontra submetida, enquanto pertencente a uma família que ocupa determinada posição no modo de produção, de dada sociedade.

Como conclusão, consideramos que investigações de natureza multidisciplinar devem centrar-se nessa gama variada de problemas

9 Reconhecemos, por um lado, a existência de tentativas de ampliar o quadro de referência teórico na análise desses fenômenos e, por outro, que a própria incorporação de variáveis sociais e psicológicas no interior de um modelo de natureza biológica, se não aumenta o poder explicativo do mesmo, porque redutos, permite, por vezes, ao menos, ampliar a forma de problematização da questão; no entanto, queremos destacar que é no marcante volume da produção paradigmal que a área encontra sua mais expressiva forma de tratamento, e assim, de lirmitacão da explicação do crescimento e do desenvolvimento infantil. 
de natureza sociológica, buscando empreender, no campo da saúde, não somente análises capazes de reter, par si, processos de crescimento e de desenvolvimento globais, mas também, igualmente, investindo em estudos de natureza epistemológica, passíveis de forne-

\section{REFERÊNCIAS BIBLIOGRÁFICAS}

1. ALTHUSSER, L. Ideologia e Aparelhos Ideológicos do Estado. Portugal/Brasil, Editorial Presença/Livraria Martins Fontes, 1974.

2. APOLLONI, T. \& COOKE, T. P. Peer behavior conceptualized as a variable influencing infant and toddler development. Amer. J. Orthopsychiat, 45 (1): 4- 17,1975.

3. BORNSCHEIN, R. L. Influence of social factors on lead exposure and child development. Environmental Health Perspectives, 62: 343-351, 1985.

4. BOLTANSKI, L. Prime Education et Morale de Classe. Paris, Monton, 1969 (Cahiers du Centre de Sociologie Europeenne, 5).

5. BOURDIEU, P. Condição de classe e exposição de classe. In: BOURDIEU, P. A Economia das Trocas Simbólicas. São Paulo, Perspectiva, 1974, pp. 3-25.

6. BOURDIEU, P. \& PASSERON, J. C. A Reprodução: elementos para uma teoria do sistema de ensino! Rio de Janeiro, Francisco Alves, 1975.

7. CASEY, P. H. e cols. Developmental intervention: a pediatric clinical review. Pediatric Clinics of North America, 33 (4): 899-923, 1986.

8. CLAUDET, P. T. et al. Algunas consideraciones sobre el crescimiento y desarrolo del niño en Centroamérica. Perspectiva Histórico Social. Revista Centroamericana de Ciências de la Salud, 7: 67 - 100, 1977.

9. GRUENWALD, P. Growth of the human fetus. I. Normal Growth and its variation. Amer. J. Obstet. Gynec., 94: 1112-9, 1966. cerem os fundamentos para a busca das relações existentes entre ambos, assim como da maneira típica de como determinadas formas de crescer e de desenvolver da criança se reproduzem sob determinadas relações sociais de classe.

10. KRAMER, S. A. Política da Pré-escola no Brasil - A Arte do Disfarce. Rio de Janeiro, Achiamé, 1982a.

11. O papel social da pré-escola. Cad. Pesq., 58: 77-X1, 1985.

12. Privação cultural e educação compensatória. Cad. Pesq., 42: 54-62, 1982b.

13. KUHN, T. S. A Estrutura das Revoluções Científicas. São Paulo, Perspectiva, 1975.

14. MARDONES-RESTAT, F. \& JONES, G. Prediction of poor infant growth. Paho Bulletin, 21(4): 341-57, 1987.

15. RALLISON, M. L. New concepts: growth disorders in children. Compreensive Therapy, 13 (12): 45-57, 1987.

16. RAPPAPORT, L. e cols. Children's descriptions of their developmental dysfunctions. Am. J. Dis Child, 137: 369-374, 1983.

17.RODE, A. \& SHEPHARD, R. J. Growth, development and acculturation a ten year comparison of Canadian inuit children. Human Biology, 56 (2): 217-230, 1984.

18. RONA, R. J. \& CHINN, S. National study of health and growth social and biological factors associated with height of children from ethnic groups living in England. Annals of Human Biology, 13 (5): 453-471, 1986.

19. SCHRAEDER, B. D. Developmental progress in very low birth weight infants during the first year of life. Nursing Research 35 (4):237-242, 1986.

20.SIEGEL, L. Reproductive, perinatal and environmental variables as predictors of development of preterns (< 1501 grams) and fullterm chi $\wedge \mathrm{l} \wedge$ aren at 5 years. Seminars in Perinatology, 6 (4): 274-279, 1982. 
